Check for updates

Cite this: RSC Adv., 2019, 9, 36097

Received 11th September 2019 Accepted 24th October 2019

DOI: 10.1039/c9ra07290j

rsc.li/rsc-advances

\section{Nano-aggregates of furan-2-carbohydrazide derivatives displaying enhanced emission with a bathochromic shift $\uparrow$}

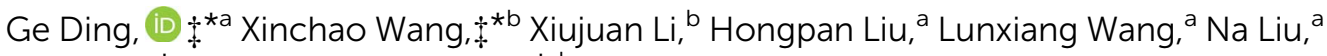 \\ Fang Gao*c and Zhenqiang Wang*d
}

\begin{abstract}
The non-fluorescent Schiff base compound C1 ( $N^{\prime}-\left(\left(4^{\prime}\right.\right.$-ethyl-3-hydroxy-[1,1'-biphenyl]-4-yl)methylene) furan-2-carbohydrazide) in organic solvent (e.g., THF) was found to produce yellow-green fluorescence emission upon addition of $\mathrm{H}_{2} \mathrm{O}$, and granular-shaped aggregates in a $\mathrm{THF} / \mathrm{H}_{2} \mathrm{O}$ mixed solution formed and exhibited obvious aggregation-induced emission (AIE). Especially its keto fluorescence band intensified dramatically, while the enol emission band remained almost unchanged. Hence, a change in fluorescence from no emission of light to emission of bright yellow-green light under a UV lamp was observed with the naked eye. In contrast, the reference compound C2 ( $N^{\prime}-\left(\left(4^{\prime}\right.\right.$-ethyl-3-methoxy-[1,1'biphenyl]-4-yl)methylene)furan-2-carbohydrazide) showed no intensified fluorescence emission under the same experimental conditions. These results indicated the significant role played by intramolecular $\mathrm{H}$-bonding in the formation of the $\mathrm{C} 1$ aggregates and the AIE process.
\end{abstract}

\section{Introduction}

There has been considerable interest recently in fluorescent materials because of their various applications in organic lightemitting diodes (OLEDs), fluorescence-based sensors, and biological cell imaging. As an emerging class of fluorescent nanomaterials, carbon dots $(\mathrm{CDs})^{1-5}$ and organic fluorescent nanomaterials have attracted sustained attention due to their superior luminescence, low toxicity, great stability, and ease of manufacture. Recently, dyes with aggregation-induced emission (AIE) properties have attracted intense research interest as a novel class of optical materials due to their molecular structures being much easier to modify and tune than the structures of CDs. ${ }^{6,7}$ AIE dyes are rotor-type molecules that have been reported to present weak fluorescence in pure organic solutions but strong fluorescence in the aggregated state. ${ }^{8,9}$ These observations have been attributed to the free motion of the rotor

${ }^{a}$ College of Materials and Chemical Engineering, Chongqing University of Arts and Sciences, Chongqing, China, 402160. E-mail: dingge1989cqu@126.com

${ }^{b}$ College of Pharmacy, Heze University, Heze, Shandong Province, China, 274000. E-mail: wxc198566@126.com

${ }^{c}$ College of Chemistry and Chemical Engineering, Chongqing University, Chongqing, China, 400044. E-mail: fanggao1971@126.com

${ }^{d}$ College of Chemistry, Chongqing Normal University, Chongqing, China, 401331. E-mail:772630581@qq.com

$\dagger$ Electronic supplementary information (ESI) available: The synthesis and characterization ( $\left.{ }^{1} \mathrm{H}-\mathrm{NMR},{ }^{13} \mathrm{C}-\mathrm{NMR}\right)$ of the dyes and Fig. S1-S7 associated with this work. See DOI: $10.1039 / \mathrm{c} 9 \mathrm{ra0} 07290 \mathrm{j}$

\$ Xinchao Wang and Ge Ding are designated as the co-first authors, who make equal contribution to this study. structures in solution consuming excited state energy by nonradiative decay to quench the emission - and the blocking of the intramolecular rotational motion and intramolecular vibration in the aggregated state activating the radiative decay pathway to yield strong fluorescence. ${ }^{10,11}$

Molecules that undergo excited-state intramolecular proton transfer (ESIPT) display a larger Stokes shift, which can effectively prevent self-absorption. Hence, a great deal of effort has been put into studying the optical properties of molecules displaying ESIPT with AIE. ${ }^{12-14}$ Several such molecules have been reported. The Yang group, ${ }^{15}$ for example, has obtained nanoscale homodispersed organic aggregates in poor solvents using the reprecipitation method and showed these aggregates displaying $\pi-\pi$ stacking interactions. ${ }^{16-18}$ Similarly, the Li and Hou group ${ }^{19}$ has realized reversible color and fluorescence changes upon UV light irradiation with good fatigue resistance. The $\mathrm{Mu}$ group $^{20}$ reported the use of AIE-displaying 2-(1-hydroxy-2naphthyl)methylene hydrazine molecules for detecting metal ions, and realized simultaneously detection of $\mathrm{Zn}^{2+}$ and $\mathrm{Co}^{2+}$ in isolated and aggregated states, respectively. However, previous studies of the mechanism of the aggregation of molecules displaying ESIPT mainly focused on the $\pi-\pi$ effect, which mainly blocks intramolecular rotational motion, but there have been few studies on the role of intramolecular H-bonding in the aggregation process. ${ }^{21-23}$

In this work, we synthesized a new conjugated chromophore carrying a proton transfer segment, and this chromophore produced enol and keto double emission bands. The intensity of the keto emission became dramatically higher during aggregation of the chromophore, while the enol emission 
remained almost unchanged. Hence, an intensified fluorescence of yellow-green light was observed with the naked eye during the aggregation process under UV lamp irradiation. A control experiment involving a reference molecule without an ESIPT segment was also conducted under the same experimental conditions, and showed no formation of aggregates in the mixture solution system and hardly any enhancement of the emission intensity. These results further indicated the important role played by intramolecular $\mathrm{H}$-bonding in the formation of aggregates and the enhancement of the emission.

\section{Results and discussion}

The formation of aggregates of $\mathbf{C} 1$ in a $\mathrm{THF} / \mathrm{H}_{2} \mathrm{O}(40 / 60, \mathrm{v} / \mathrm{v})$ solution was monitored using scanning electron microscopy (SEM) (Fig. 1). During the first five minutes of aggregation, an amorphous state was observed. With increasing aggregation time (such as at $12 \mathrm{~h}$ ), granular-shaped particles with dimensions of 100-200 $\mathrm{nm}$ were seen. However, under the same experimental conditions, the reference C2 in the $\mathrm{THF} / \mathrm{H}_{2} \mathrm{O}$ mixed solution or in other mixed solution systems (such as $\mathrm{EtOH} / \mathrm{H}_{2} \mathrm{O}$, DMF $/ \mathrm{H}_{2} \mathrm{O}$ ) was not observed to form nanoaggregates. These results indicated a vital role for intramolecular H-bonding in the formation of aggregates of the target C1. An X-ray diffraction (XRD) pattern of powder C1 displayed intense diffraction peaks, while the reference $\mathbf{C 2}$ yielded no obvious diffraction peaks (Fig. S1, ESI $\dagger$ ); these results suggested the formation of a crystalline state and a harmonious arrangement by $\mathbf{C 1}$ molecules in the solid state.

The sizes of the target dye $\mathbf{C 1}$ aggregates in the mixed THF/ $\mathrm{H}_{2} \mathrm{O}$ solvent at various aggregation times were also measured using dynamic light scattering (DLS). The diameters of the aggregates in the mixed system were in the range $10-30 \mathrm{~nm}$ at an aggregation time of $30 \mathrm{~min}$, and approximately $160-210 \mathrm{~nm}$ at $12 \mathrm{~h}$ (Fig. S2, ESI $\dagger$ ). These results were in accordance with those obtained with the SEM images.

Fig. 2(a) shows UV-visible absorption spectra of C1 and C2 in pure THF solutions. Each of these spectra showed two absorption peaks: one at $\sim 326 \mathrm{~nm}$ ascribed to $(\mathrm{n}, \pi)$ transition due to the presence of imino group; and the other at about $350 \mathrm{~nm}$, which may have been produced by $\pi, \pi$ transition due to intramolecular charge transfer. Furthermore, the absorption maxima of $\mathbf{C 1}$ were a bit red-shifted compared with those of $\mathbf{C 2}$.

As shown in Fig. 2(b), C1 yielded two emission bands in dilute THF with a small fluorescence quantum yield $(\Phi, 0.0219)$, while C2 yielded only a single emission band. For C1, the emission band at 370-425 $\mathrm{nm}$ was attributed to enol emission, while that at $475-550 \mathrm{~nm}$ was assigned to keto emission
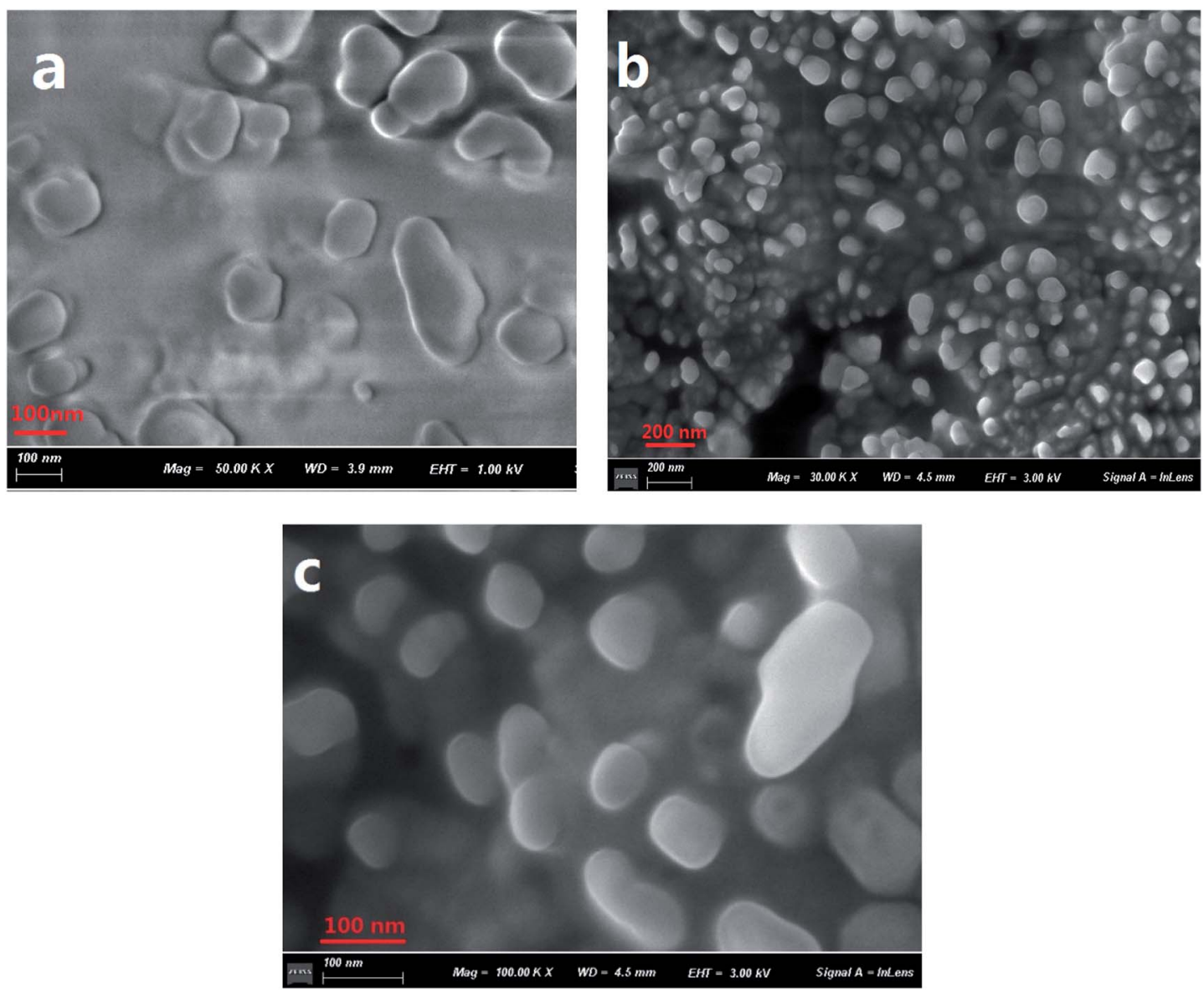

Fig. 1 SEM images of $\mathrm{C} 1$ aggregate formation in a THF/ $\mathrm{H}_{2} \mathrm{O}(40 / 60, \mathrm{v} / \mathrm{v})$ solution $\left(2 \times 10^{-5} \mathrm{~mol} \mathrm{~L}^{-1}\right)$ at $5 \mathrm{~min}(\mathrm{a})$ and $12 \mathrm{~h}(\mathrm{~b}$ and $\mathrm{c})$. A magnified image is shown in (c). 

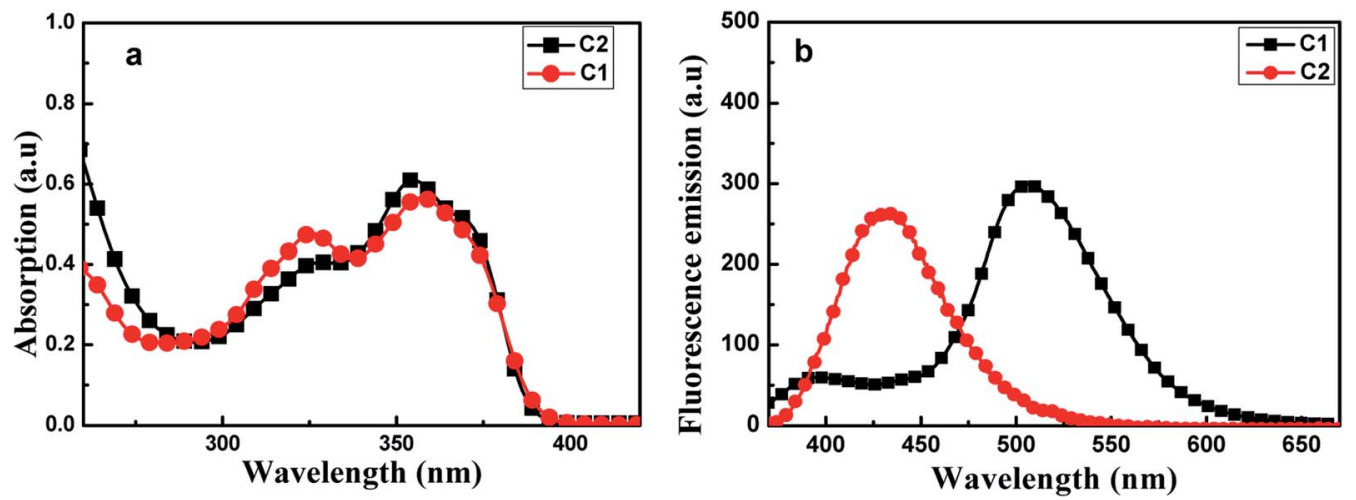

Fig. 2 Absorption spectra (a) and fluorescence emission spectra (b) of C1 and C2, each at a concentration of $2 \times 10^{-5} \mathrm{~mol} \mathrm{~L}^{-1}$ in THF. The excitation wavelength used was $350 \mathrm{~nm}$.

generated by an ESIPT reaction. This emission property proved that a proton transfer reaction can occur in $\mathbf{C 1}$, in its excited state, due to the presence of intramolecular H-bonding (Fig. S3, ESI $\dagger$ ). The keto emission band of $\mathbf{C} \mathbf{1}$ showed a larger Stokes $\operatorname{shift}(\sim 152 \mathrm{~nm})$, which could be attributed to energy loss during internal proton transfer in the excited state.

The optical properties of aggregates of C1 in various THF/ $\mathrm{H}_{2} \mathrm{O}$ solutions with different volume ratios of THF to $\mathrm{H}_{2} \mathrm{O}$ were measured. For all such ratios tested, the absorption intensity of C1 decreased significantly with increasing aggregation time (Fig. S4(a), ESI†), but did so most significantly when the ratio was increased to $4: 6$, where it displayed a significant red shift (of about $6 \mathrm{~nm}$ ) relative to the maximum absorption peak in pure THF. The decrease of absorption intensity may have been due to the continuous consumption of free molecules via formation of intermolecular $\pi-\pi$ interactions. In contrast, the absorption spectra of $\mathbf{C 2}$ remained nearly unchanged at the same experimental conditions (Fig. S4(b), ESI $\dagger$ ).

The effects of water volume fraction $\left(f_{\mathrm{w}}\right)$ in the $\mathrm{THF} / \mathrm{H}_{2} \mathrm{O}$ mixed solvent on the fluorescence intensities of $\mathbf{C} \mathbf{1}$ and $\mathbf{C} \mathbf{2}$ were also investigated (Fig. 3). The emission spectra of $\mathbf{C} \mathbf{1}$ for different ratios of THF to $\mathrm{H}_{2} \mathrm{O}$ (water fractions from 0 to $90 \%, \mathrm{v}$ / v) were obtained at an aggregation time of $12 \mathrm{~h}$ (Fig. 3(a)). These spectra showed that the emission intensity was greatest, with a fluorescence quantum yield of 0.435 (19.86 times than that in pure THF solution), when the water fraction in the $\mathrm{THF} / \mathrm{H}_{2} \mathrm{O}$ mixed solution was $60 \%$, which further indicated C1 in THF/ $\mathrm{H}_{2} \mathrm{O}$ to be AIE active. In contrast, reference $\mathbf{C 2}$ presented no obvious change in emission as the $\mathrm{THF} / \mathrm{H}_{2} \mathrm{O}$ ratio was changed (Fig. 3(b)). The results further indicated that intramolecular $\mathrm{H}^{-}$ bonding further rigidified the molecular structure and activated the restriction intramolecular rotation (RIR) process except for intermolecular $\pi-\pi$ interactions.

Fluorescence emission spectroscopic measurements in THF/ $\mathrm{H}_{2} \mathrm{O}(40 / 60, \mathrm{v} / \mathrm{v})$ were taken at various aggregation times. As shown in Fig. 4(a), the target $\mathbf{C} 1$ appeared to show weak fluorescence emission in pure THF, whereas the emission of its aggregates in a $(40 / 60, \mathrm{v} / \mathrm{v}) \mathrm{THF} / \mathrm{H}_{2} \mathrm{O}$ mixed solution was dramatically stronger. The fluorescence emission bands assigned to both enol and keto emissions gradually increased in intensity during the first 45 minutes $(\Phi, 0.158,45 \mathrm{~min})$, but with a somewhat quicker increase for the keto emission than for the enol emission. Interestingly, the keto emission showed a persistently remarkable increase in intensity after 45 minutes and until 12 hours, after which the intensity remained unchanged. Meanwhile, it displayed an obvious red-shift $(7 \mathrm{~nm})$
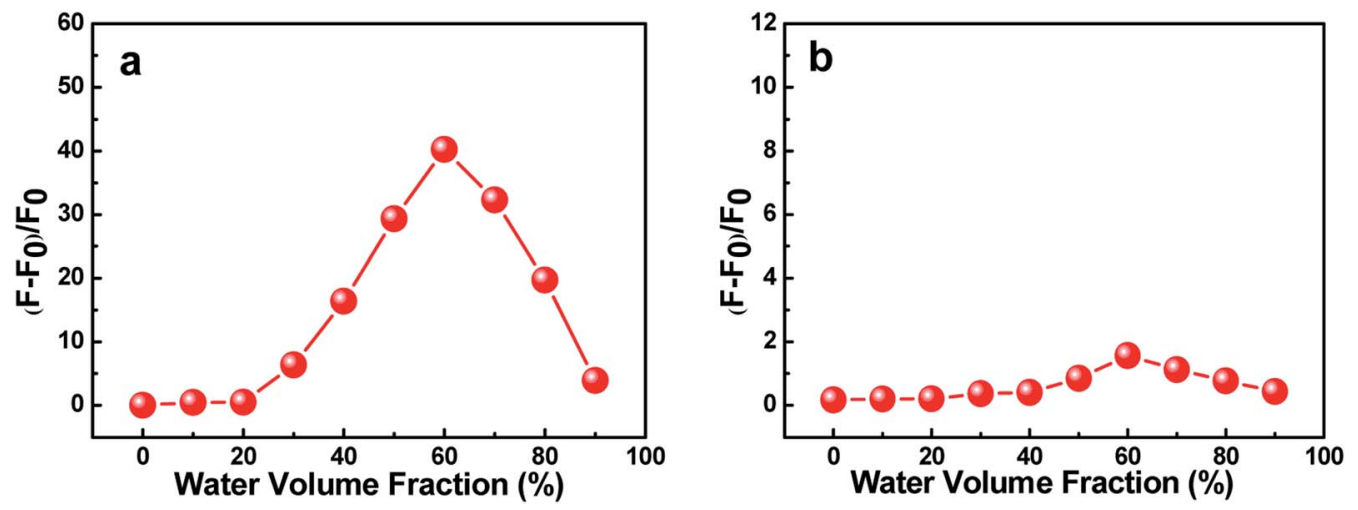

Fig. 3 Effects of the water volume fraction $\left(f_{\mathrm{w}}\right)$ of $\mathrm{C} 1$ (a) and $\mathrm{C} 2$ (b) on their fluorescence intensities in $\mathrm{THF} / \mathrm{H}_{2} \mathrm{O}$ mixed solvents at $12 \mathrm{~h}$. The concentration of $\mathrm{C} 1$ and that of $\mathrm{C} 2$ were both $2 \times 10^{-5} \mathrm{~mol} \mathrm{~L}^{-1}$. 

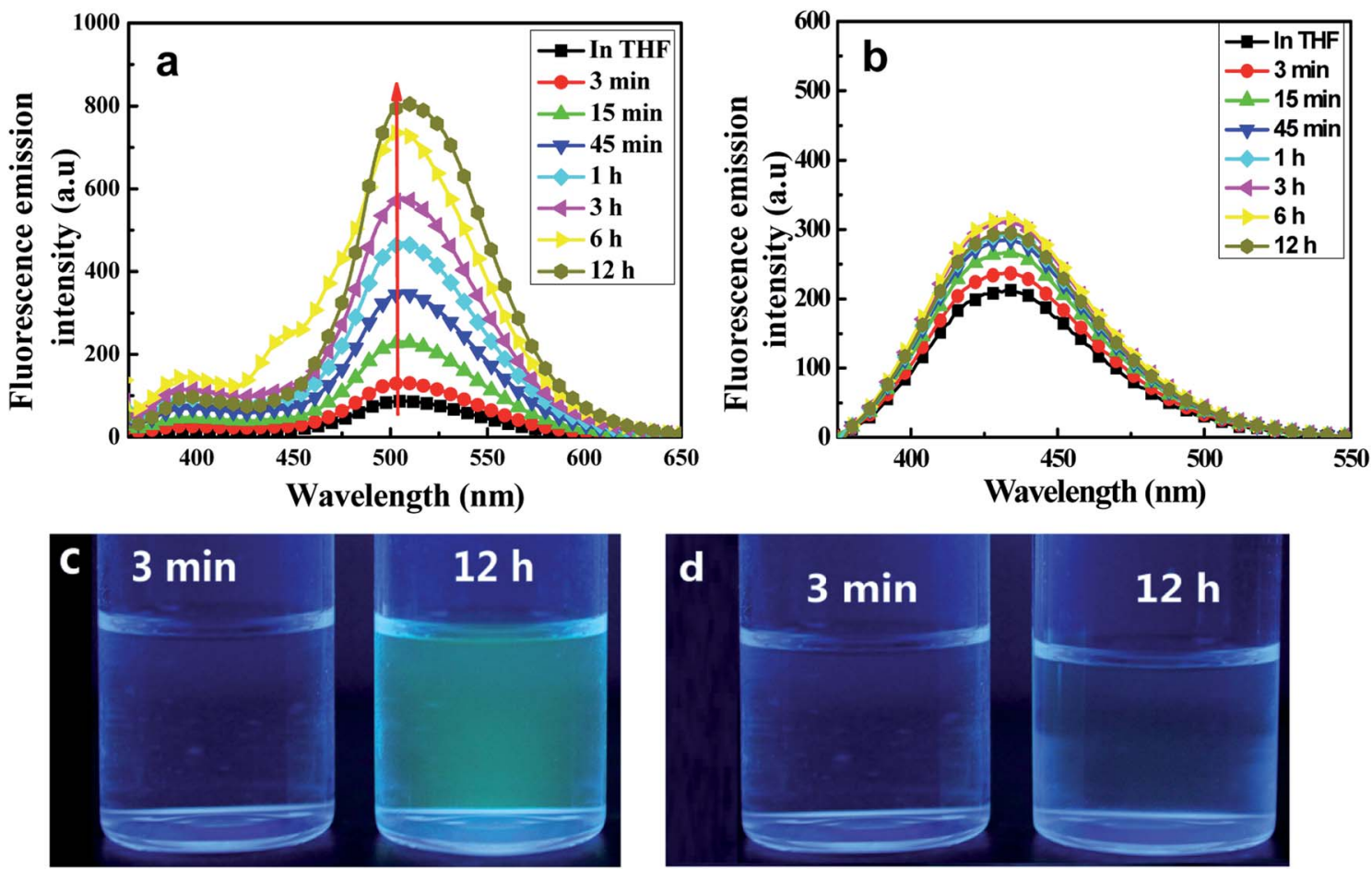

Fig. 4 Emission spectra of $\mathrm{C} 1$ (a) and C2 (b), each at a concentration of $2 \times 10^{-5} \mathrm{~mol} \mathrm{~L}^{-1}$ in a mixed THF/ $\mathrm{H}_{2} \mathrm{O}(40 / 60$, v/v) solution, at various time points. The excitation wavelength used was $350 \mathrm{~nm}$. Photographs at the indicated time intervals of C1 (c) and C2 (d) under UV lamp irradiation.

compared with that in the pure THF solution. In contrast, the intensity of the enol emission hardly changed after 45 minutes. Thus, an intense yellow-green fluorescence emission was observed under UV lamp irradiation (Fig. 4(c)).

The remarkably intensified emission and red-shift of the emission and absorption of $\mathbf{C 1}$ in $\mathrm{H}_{2} \mathrm{O} / \mathrm{THF}(60 / 40, \mathrm{v} / \mathrm{v})$ compared with that in pure THF further indicated the formation of J-type aggregates (head-to-tail arrangement). ${ }^{15}$ The large Stokes shift (165 nm) of $\mathbf{C 1}$ exhibited in $\mathrm{H}_{2} \mathrm{O} / \mathrm{THF}(60 / 40, \mathrm{v} / \mathrm{v})$ indicated that the ESIPT process can smoothly proceed in the aggregated state due to the lack in this state of polar solvents disrupting intramolecular hydrogen bonds. At the same time, in the control experiment, the reference molecule without any ESIPT segment could not form aggregates in the $\mathrm{THF} / \mathrm{H}_{2} \mathrm{O}$ mixture and the emission intensity showed almost no change (Fig. 4(c)). Furthermore, infrared (IR) spectra of C1 samples in pure THF solution, solid state, and aggregate state, respectively, were obtained (Fig. S5, ESI $\dagger$ ). The hydroxyl peak of $\mathbf{C 1}$ at about $3439 \mathrm{~cm}^{-1}$ was observed here to be much wider than that of the free hydroxyl group. Meanwhile, the positions of the $-\mathrm{OH}$ peak in the THF solution $\left(0.1 \mathrm{~mol} \mathrm{~L}^{-1}\right)$, solid state and aggregate state spectra were nearly the same. Therefore, intramolecular $\mathrm{H}$ bonding rather than intermolecular H-bonding was concluded to be present in $\mathbf{C 1}$ both in solution and the aggregate state; this result further indicated the important role played by intramolecular $\mathrm{H}$-bonding in the formation of aggregates and emission enhancement of $\mathbf{C 1}$ except for intermolecular $\pi-\pi$ interaction, ${ }^{\mathbf{2 4 - 2 6}}$ which led to the RIR process and rigidified the non-planar configuration in the J-type aggregation state (Fig. S6, ESI†).

In fact, a bright yellow-green emission of C1 was evidently observed in the solid state under UV lamp irradiation (Fig. S7, ESI $\dagger$ ). While the reference dye $\mathbf{C 2}$ did not display brilliant emission in solid state, in accordance with results discussed above.

\section{Experimental}

The synthetic route to dyes $\mathbf{C 1}$ and $\mathbf{C 2}$ is shown in Scheme 1. The details of the synthesis process are shown in ESI. $\uparrow$ Nanoaggregates were prepared by rapidly injecting $50 \mu \mathrm{L}$ of THF solutions of $\mathbf{C} 1$ and $\mathbf{C 2}\left(2 \times 10^{-3} \mathrm{~mol} \mathrm{~L}^{-1}\right)$, respectively, into $50 \mathrm{~mL}$ samples of a THF/ $\mathrm{H}_{2} \mathrm{O}$ mixed solution (with $\mathrm{H}_{2} \mathrm{O} / \mathrm{THF}$ (v/ v) ratios from $10 \%$ to $90 \%$, respectively) and then vigorously stirring the resulting mixtures at room temperature. When water was appropriately added to the mixed system, the polarity of the mixed system changed dramatically and the free molecules began to aggregate, which inhibited the intramolecular free rotation and non-radiative deactivation channels to some extent through intramolecular H-bonding or $\pi-\pi$ interactions. Thus, the fluorescence emission was dramatically enhanced. A simulation of the growth of the nano-aggregates is shown in Scheme 2.

A Bruker $400 \mathrm{MHz}$ NMR instrument was used to record ${ }^{1} \mathrm{H}$ and ${ }^{13} \mathrm{C}$ nuclear magnetic resonance (NMR) spectra of the samples. A Fourier transform infrared spectrometer was used to acquire IR spectra of the target molecules. Here, an aqueous 


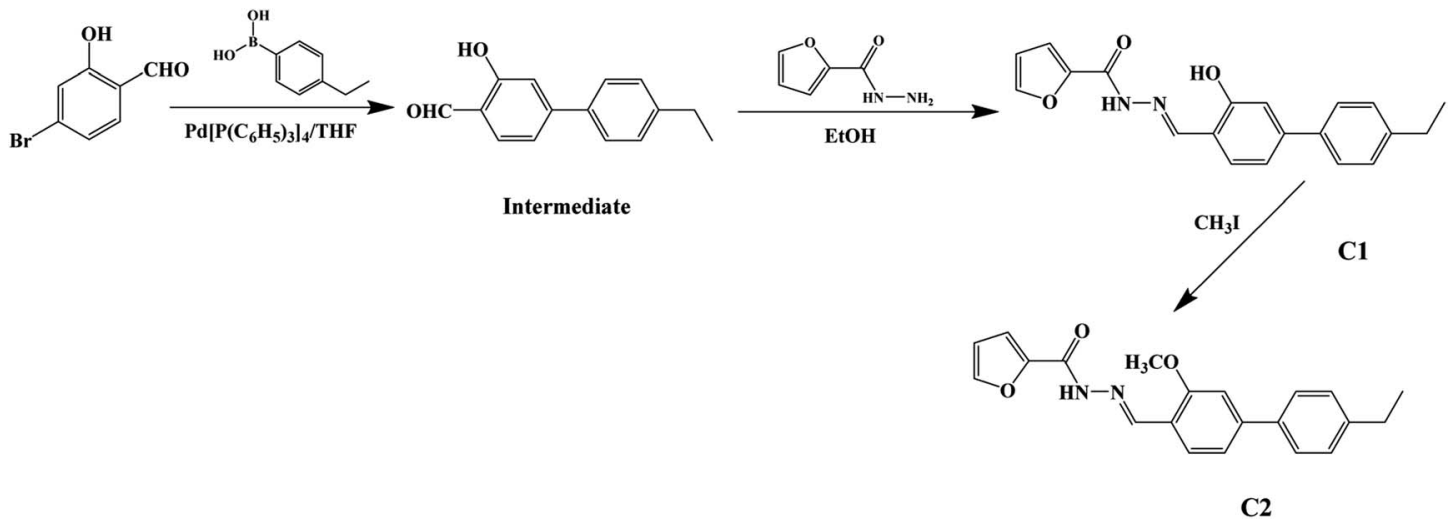

Scheme 1 Synthetic routes to the target $\mathrm{C} 1$ and reference $\mathrm{C} 2$.

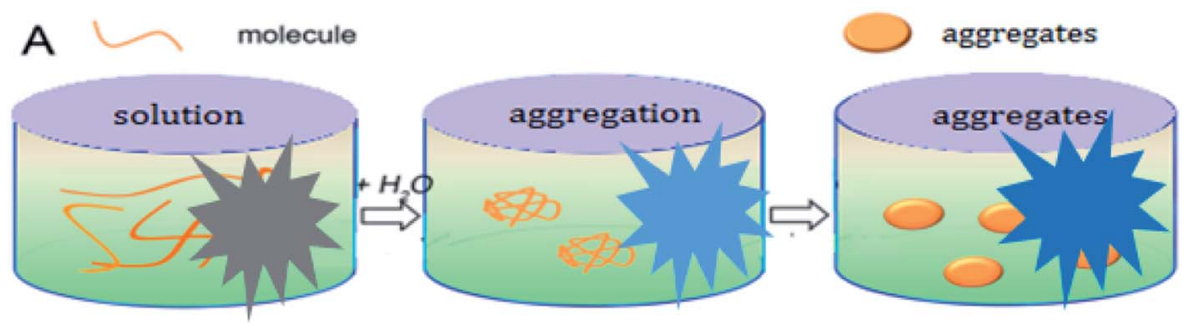

Scheme 2 A simulation of the growth of nano-aggregates.

dispersion of sample dye aggregates in a THF/ $\mathrm{H}_{2} \mathrm{O}(40 / 60, \mathrm{v} / \mathrm{v})$ mixture was titrated gradually upon the surface of a plate to prepare predetermined samples of dye aggregates, the solvents were evaporated rapidly, and then the IR spectra of the target dyes were acquired. A TU1901 spectrophotometer from Beijing PUXI General Equipment Limited Corporation was used to acquire UV-visible absorption spectra. The fluorescence spectra were acquired by using a Shimadzu RF-531PC spectrofluorophotometer. The surface morphologies of the aggregates were visualized using a scanning electron microscope from JeolJSM-3.5 CF-Japan. Dynamic light scattering (DLS) experiments were performed using an He-Ne laser light source $(\lambda, 633 \mathrm{~nm})$, photomultiplier detector, and digital correlator (Malvern Instruments, UK).

\section{Conclusions}

Overall, the dramatic emission enhancement of C1 was achieved through an aggregation process in a mixed solution. By comparing results for $\mathbf{C} 1$ and $\mathbf{C 2}$, intramolecular H-bonding was concluded to have promoted the aggregation of $\mathbf{C 1}$ in the $\mathrm{THF} / \mathrm{H}_{2} \mathrm{O}$ mixed solution, and to have hence further enhanced the intensity of the keto peak emission during a certain part of the aggregation time course. As a consequence, a remarkable change from a lack of fluorescence emission to emission of yellow-green light under UV lamp irradiation was observed, which may have strong potential applications in chemical sensing, cell imaging, and so on.

\section{Conflicts of interest}

There are no conflicts to declare.

\section{Acknowledgements}

We thank the Chongqing Natural Science Foundation for financial support (Grant No. cstc2018jcyjAX0446). We also appreciate financial support from the Chongqing University of Arts and Sciences and Heze University (Grant No. 2017RCH03, 2017RCH07, XY16BS33 and XY17KJ10).

\section{References}

1 S. Y. Lu, L. Z. Sui, J. J. Liu, S. J. Zhu, A. M. Chen, M. X. Jin and B. Yang, Adv. Mater., 2017, 29, 1603443-1603449.

2 S. Y. Tao, S. Y. Lu, Y. J. Geng, S. J. Zhu, S. A. T. Redfern, Y. B. Song, T. L. Feng, W. Q. Xu and B. Yang, Angew. Chem., Int. Ed., 2018, 57, 2393-2398.

3 S. Y. Lu, L. Z. Sui, M. Wu, S. J. Zhu, X. Yong and B. Yang, Adv. Sci., 2019, 6, 1801192-1801200.

4 Q. Qi Wang, S. J. Zhang, B. Y. Wang, X. Y. Yang, B. Zou, B. Yang and S. Y. Lu, Nanoscale Horiz., 2019, 4, 1227-1231.

5 T. Geng, T. L. Feng, Z. W. Ma, Y. Cao, Y. P. Chen, S. Y. Tao, G. J. Xiao, S. Y. Lu, B. Yang and B. Zou, Nanoscale, 2019, 11, 5072-5079.

6 R. Wieneke and R. Tamp, Angew. Chem., Int. Ed., 2019, 131, 2-15. 
7 C. L. Fan, S. H. Luo and H. P. Qi, Luminescence, 2016, 31, 423427.

8 H. Takakusa, K. Kikuchi, Y. Urano, S. Sakamoto, K. Yamaguchi and T. Nagano, J. Am. Chem. Soc., 2002, 124, 1653-1657.

9 Z. G. Song, R. T. K. Kwok, E. G. Zhao, Z. K. He, Y. N. Hong and J. W. Y. Lam, ACS Appl. Mater. Interfaces, 2014, 6, 1724517254.

10 X. B. Wang, Z. Y. Zhang, X. Y. Ma, J. H. Wen, Z. R. Geng and Z. L. Wang, Talanta, 2015, 137, 156-166.

11 P. X. Pei, J. H. Hu, P. W. Ni, C. Long, J. X. Su and Y. Sun, RSC Adv., 2017, 7, 46832-46838.

12 Z. H. Cui, H. Lischka, H. Z. Beneberu and M. Kertesz, J. Am. Chem. Soc., 2014, 136, 5539-5542.

13 Y. Q. Niu, T. He, J. Song, S. P. Chen, X. Y. Liu, Z. G. Chen, Y. J. Yu and S. G. Chen, Chem. Commun., 2017, 53, 75417544.

14 P. Liu, W. Li, S. Guo, D. Xu, M. Wang and J. Shi, ACS Appl. Mater. Interfaces, 2018, 10, 23667-23673.

15 Y. Qian, S. Y. Li, G. Q. Zhang, Q. Wang, S. Q. Wang, H. J. Xu, C. Z. Li, Y. Li and G. Q. Yang, J. Phys. Chem. B, 2007, 111, 5861-5868.

16 K. Li and B. Liu, Chem. Soc. Rev., 2014, 43, 6570-6597.
17 R. Hu, N. L. C. Leung and B. Z. Tang, Chem. Soc. Rev., 2014, 43, 4494-4562.

18 J. Zhou, Z. Chang, Y. Jiang, B. He, M. Du, P. Lu, Y. Hong, H. S. Kwok, A. Qin, H. Qiu, Z. Zhao and B. Z. Tang, Chem. Commun., 2013, 49, 2491-2493.

19 L. L. Wang, Y. Y. Li, X. J. You, K. Xu, Q. Feng, J. M. Wang, Y. Y. Liu, K. Li and H. W. Hou, J. Mater. Chem. C, 2017, 5, 65-72.

20 X. Cao, X. Zeng, L. Mu, Y. Chen, R. X. Wang, Y. Q. Zhang, J. X. Zhang and G. Wei, Sens. Actuators, B, 2013, 177, 493499.

21 M. Wang, Y. Xu, Y. Liu, K. Gu, J. Tan, P. Shi, D. Yang, Z. Guo, W. Zhu and X. Guo, ACS Appl. Mater. Interfaces, 2018, 10, 25186-25193.

22 T. Kakuta, T. A. Yamagishi and T. Ogoshi, Acc. Chem. Res., 2018, 51, 1656-1666.

23 J. Orrego-Hernández and J. Portilla, J. Org. Chem., 2017, 82, 13376-13385.

24 Y. N. Liu, Z. J. Xu, J. H. Zhang, J. Cheng, M. H. Miao and D. H. Zhang, Dyes Pigm., 2019, 170, 107586.

25 S. Hisamatsu, H. Masu, M. Takahashi, K. Kishikawa and S. Kohmoto, Cryst. Growth Des., 2015, 15, 2291-2302.

26 M. Gao, S. W. Li, Y. H. Lin, Y. Geng, X. Ling, L. C. Wang, A. J. Qin and B. Z. Tang, ACS Sens., 2016, 1, 179-184. 